\title{
Yield gaps and nutrients use efficiency of apple tree (golden delicious/MM106) in the middle Atlas Mountains of Morocco
}

\author{
Rachid Razouk, Abdellah Kajji, Khalid Daoui, Jamal Charafi, Mohamed Alghoum
}

National Agricultural Research Institute, BP. 578, Meknes, Morocco.

\begin{abstract}
The main objective of this work was to evaluate use efficiency of nitrogen, phosphorus, potassium, calcium and magnesium in adult apple orchards in the Middle Atlas of Morocco and to establish preliminary reference norms for fertilizing this crop under local conditions. The study was based on soil and leaf analysis and data with regard to farming practices and yield on forty apple orchards (cv. Golden delecious/MM106) where nineteen are growing on siltyclay soil and twenty-one on sandy-loam soil. The results showed significant correlations between leaf content for each nutrient and yield level following polynomial equations, thereby indicating local reference norms for apple leaf analysis. Moreover, correlations were significant between leaf and soil contents that permitted to determine apple needs in nitrogen fertilizer and references norms for soil richness in phosphorus, potassium, calcium and magnesium to obtain yield potential in the study region. However, the found norms are less than international standards because of feebleness of yield level in the study region, largely related to deficient cultural practices adopted by farmers. In addition, investigation of leaf nutrients ratios $N / K$, $\mathrm{N} / \mathrm{Ca}, \mathrm{K} / \mathrm{Ca}, \mathrm{K} / \mathrm{Mg}$ and $\mathrm{Ca} / \mathrm{Mg}$ showed that there was disharmony in uptake of these nutrients originating particularly from high soil richness in Ca and $\mathrm{Mg}$. Taking into account these considerations, the found references norms can be applied only under the adopted farming practices. Nevertheless, by improving local practices, reference values may change.
\end{abstract}

Keywords - apple tree, leaf analysis, macronutrients, Morocco, soil analysis.

\section{INTRODUCTION}

In order to be more competitive and ensure the sustainability of quality of their soils, farmers should constantly improve fertilization efficiency of their crops [1]. This objective would be achieved through determination of critical level for each nutrient that designates its concentration in soil above which crops does not respond to a supply of this nutrient [2].
Determining this level usually based on trials, with a single factor, of escalating doses of a nutrient on crop yield at different levels of soil richness [3, 4].

In fruit trees, precise determination of the nutrient requirements is particularly difficult. Indeed, nutrients and metabolites may be stored in wood for use them at the next year by growing shoots [5]. To these difficulties are added those related to nutrients migration in soil and to particularity of tree root system [6]. Soil analysis permits to quantify soil richness in nutrients and to estimate fertilizer requirements but they provide no indication as their use by trees. However, leaf analysis is an effective tool for assessing nutritional status of trees and for readjustment of fertilizer requirements taking into account factors that may affect nutrients availability and their uptake by roots [7]. Thus, a deficiency in phosphorus would be explained by a low concentration of this nutrient in soil, an inhibition of its uptake caused by a high concentration in active limestone, or by combined effect of these two conditions [8]. Leaf analysis reveals also deficiencies induced by some fertilization practices. For example, a deficiency in potassium would be induced by nitrogen fertilization in soil containing a low concentration in potassium because the vegetative growth resulting from nitrogen generates important requirements in potassium [9]. Leaf analysis provides information about fertilizers assimilation and for this reason it complete soil analysis [10].

In Morocco, works on this topic, in particular for apple tree, are limited. Until now, interpretation of soil and leaf analyses for the Moroccan apple orchards based on reference norms established on others countries such USA, France, Netherlands, United Kingdom and South Africa. Establishment of norms under local conditions is therefore necessary for an efficient management of fertilization in Moroccan orchards taking into account local practices and production performances. The present work aims to establish recommendations for an efficient fertilization of adult apple tree in the region of Imouzzer Kandar in the Middle Atlas of Morocco, which constitutes a concentration area for apple production in 
northern Morocco. It is also a contribution to identify the Moroccan norms of soil and leaf analysis for apple tree concerning nitrogen, phosphorus, potassium, calcium and magnesium.

\section{MATERIALS AND METHODS}

\subsection{Cultural conditions}

Study was carried out in farmer's fields in the region of Imouzzer Kandar in northern Morocco. The climate of this region is characterized by cold winters with a minimum temperature of $-10{ }^{\circ} \mathrm{C}$ and hot summers with a maximum temperature of $40{ }^{\circ} \mathrm{C}$. The annual average of precipitations is $500 \mathrm{~mm}$ concentrated in autumn and spring. However, summer is characterized by a rainfall deficit (fig.1).

The experiment consisted in characterization of nutritional status and production of forty adult apple tree orchards (cultivar Golden delicious in association with Starking delicious as pollinator and grafted on MM 106 rootstock) 12-15 years old and planted at a density of 667 trees/ha $(5 \times 3 \mathrm{~m})$ among farmers orchards in relation to their usual farming practices. The forty orchards were selected from all parts of the study area in which nineteen orchards were planted on silty-clay soils and twenty-one orchards on a sandy-loam soil. The orchards were irrigated by submersion every week from flowering to fruit harvest (April - October) and practically pruned following the same manner, but differently fertilized. For all orchards, the intakes of nutrients concerned only nitrogen, phosphorus and potassium with amounts ranged from 6 to $165 \mathrm{~kg} /$ ha for nitrogen, from 0 to $135 \mathrm{~kg} / \mathrm{ha}$ for phosphorus and from 0 to 112 for potassium. Weighed yield ranged from 8 to $26 \mathrm{t} / \mathrm{ha}$.

\subsection{Measurements}

\subsubsection{Soil analysis}

Soil analysis was realized during dormancy period of apple tree in November on two soil horizons: $0-35 \mathrm{~cm}$ and $35-70 \mathrm{~cm}$. Analysis were performed by the following methods: particle size by pipette method [11], total and active limestone by Drouineau method [12], $\mathrm{pH}$ by titration [13], organic matter by Walkley and Black method [14], total nitrogen by kjeldhal method [15], available phosphorus by Joret and Hebert method [16], exchangeable potassium using ammonium acetate [17] and exchangeable calcium and magnesium by complexometry [18].

Physical and chemical characteristics of soil, both siltyclay and sandy-loam, are indicated in Table 1 showing that the soil for all experimental orchards was alkaline, moderately calcareous, rich in organic matter and little charged in rocks.

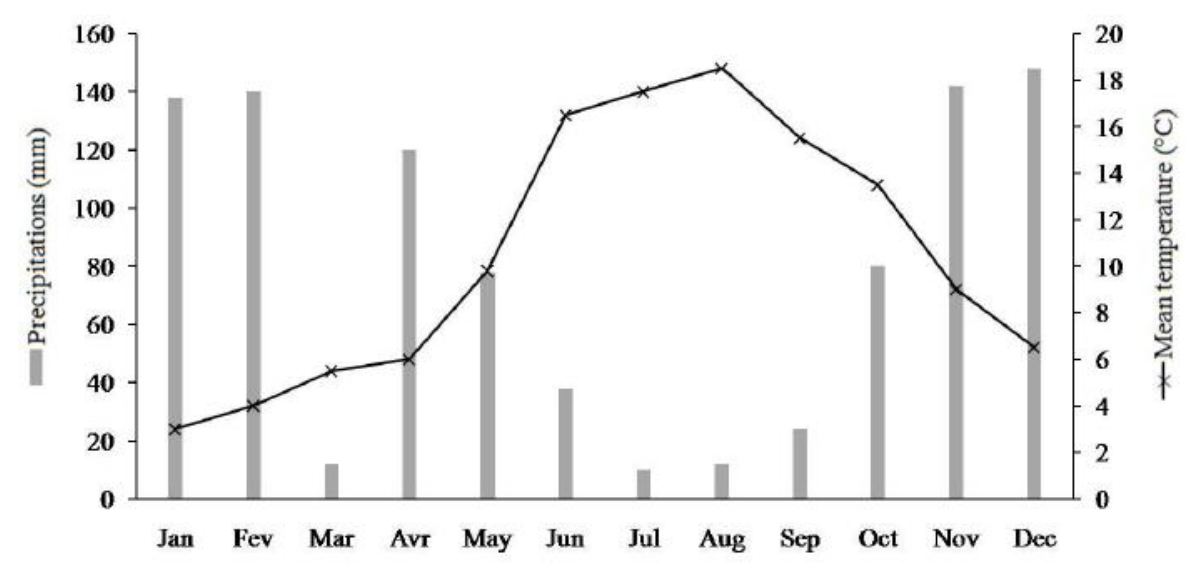

Fig.1: Monthly values of precipitation and mean temperature in the study region

Table 1. Physical and chemical characteristics of soil in the experimental orchards

\begin{tabular}{lllll}
\hline & \multicolumn{2}{l}{ Orchards on silty-clay soil } & \multicolumn{2}{l}{ Orchards on sandy-loam soil } \\
\hline & $0-35 \mathrm{~cm}$ & $35-70 \mathrm{~cm}$ & $0-35 \mathrm{~cm}$ & $35-70 \mathrm{~cm}$ \\
\hline Fine soil (\%) & 88.42 & 85.75 & 88.36 & 85.35 \\
Total limestone (\%) & 33.45 & 31.71 & 35.30 & 33.04 \\
Active limestone (\%) & 11.58 & 10.50 & 11.53 & 10.98 \\
$\mathrm{pH}$ & 7.81 & 8.02 & 7.83 & 8.04 \\
Organic matter (\%) & 2.93 & 1.47 & 2.91 & 1.48 \\
\hline
\end{tabular}




\subsubsection{Leaf analysis}

Leaves were taken with their petioles during the last decade of June 65 to 75 days after full flowering stage, from middle portion of growing shoots. At this period, nutrients content of apple leaves are relatively stable and for which references norms have been previously established [19]. Leaves samples were conveyed immediately to the laboratory where they were placed in a hydrochloric acid solution $0.1 \%$, washed thoroughly with distilled water, dried at $70{ }^{\circ} \mathrm{C}$ for 48 hours and finely grinded.

Analysis concerned leaf content in nitrogen, phosphorus, potassium, calcium and magnesium following methods described by Rayan et al. [15]: nitrogen by kjeldhal method, phosphorus by spectrophotometer, potassium by flam photometer, calcium and magnesium by complexometry.

\subsection{Statistical analysis}

Data was used to evaluate significance of correlations established between soil richness in nutrients and nutritional status of apple tree based on leaf analysis and the obtained fruit yields. The significance of correlations was evaluated following Pearson test using SPSS software (version 17.0).

\section{RESULTS AND DISCUSSION}

\subsection{Reference norms for leaf analysis}

Apple yield varied with leaf nutrients contents following significant polynomial equations. According to determination coefficients of the found equations, apple yield was more determined by leaf potassium and nitrogen better than phosphorus, calcium and magnesium. This result is in line with the findings of Cheng and Raba [19] on Gala apple tree, of Raina et al. [20] on pear tree and of Kumar et al. [21] on kiwi tree. The curves of these equations indicated that reference norms of leaf analysis for high apple yield in the study site were 2.80-3.10 for nitrogen, $0.20-0.22$ for phosphorus, 1.90-2.10 for potassium, 1.30-1.45 for calcium and 0.25-0.28 for magnesium (figure 2). These norms are higher than those recommended by Mahhou [22] in Sais plain in Morocco on Golden delicious grafted on rootstock MM 106 for nitrogen and phosphorus that are respectively 2.35 and 0.14 , but they are similar for potassium. These differences may be related to a variation in agricultural situations, especially to a difference in apple yield potential which is lesser in Sais plain compared to the mountainous region of Imouzzer Kandar because mainly of an insufficiency in chilling availability [23]. In comparison to other countries, these norms are similar to those adopted in France regarding all the analyzed macronutrients except nitrogen [5]. For this nutrient, the found norms are similar to the United Kingdom norms [24]. While in comparison with the American norms, the concordances were found only for phosphorus and calcium [25].

The found norms imply that the optimal ratios between leaf nutrient concentrations should be ranged from 1.38 to 1.63 for the ratio of $\mathrm{N} / \mathrm{K}, 2$ to 2.38 for $\mathrm{N} / \mathrm{Ca}, 1.31$ to 1.61 for $\mathrm{K} / \mathrm{Ca}, 6.55$ to 8.40 for $\mathrm{K} / \mathrm{Mg}$ and 4.48 to 5.80 for $\mathrm{Ca} / \mathrm{Mg}$. These ranges values of ratios are in line with the France norms for $\mathrm{N} / \mathrm{K}, \mathrm{K} / \mathrm{Mg}$ and $\mathrm{Ca} / \mathrm{Mg}$ and with United Kingdom norms for $\mathrm{N} / \mathrm{Ca}, \mathrm{K} / \mathrm{Ca}$ and $\mathrm{Ca} / \mathrm{Mg}[5,24]$.

Our results showed that the optimal values of ratios of $\mathrm{N} / \mathrm{K}$ and $\mathrm{Ca} / \mathrm{Mg}$ were effectively recorded in the most productive orchards where yields are higher than $22 \mathrm{t} / \mathrm{ha}$, thereby indicating that there was a harmony in uptake of these nutrients in soil [26]. However, ratios values of $\mathrm{N} / \mathrm{Ca}, \mathrm{K} / \mathrm{Ca}$ and $\mathrm{K} / \mathrm{Mg}$ in these orchards were generally lesser than the optimal ranges (table 2). This disharmony between these nutrients is originating from an excessive uptake of $\mathrm{Ca}$ and $\mathrm{Mg}$ since there concentrations in leaf are higher, exceeding the optimal values by an average of $0.14 \%$ for $\mathrm{Ca}$ and $0.02 \%$ for $\mathrm{Mg}$. The origins of excesses in $\mathrm{Ca}$ and $\mathrm{Mg}$ are related primarily to their high concentration in soil [27]. However, other factors may induce excess in $\mathrm{Ca}$ and $\mathrm{Mg}$ uptake such as the use of nitrogen as nitrate $\left(\mathrm{NO}_{3}\right)$, high contents in phosphorus and low amounts of potassium [28].

Nevertheless, the recorded excess in leaf $\mathrm{Ca}$ and $\mathrm{Mg}$ did not induce a reduction in apple yield. In fact, these tow nutrients are not toxic for plants even at high concentrations, but they induce indirect effects [29]. The high soil contents in $\mathrm{Ca}$ and $\mathrm{Mg}$ generate an increase in $\mathrm{pH}$, which reduces the uptake of certain nutrients such as boron, iron, manganese and zinc. Because they are cations, they compete therefore with the uptake of other cations such potassium $\left(\mathrm{K}^{+}\right)$and ammonium $\left(\mathrm{NH}_{4}{ }^{+}\right)$and may cause a deficiency of these nutrients [30].

\subsection{Reference norms for soil analysis}

The relationships between soil and leaf nutrient content were tested by logarithmic regression analysis regarding phosphorus, potassium, calcium and magnesium taking into account both the initial soil richness and the applied amount of fertilizers. However, for nitrogen, relationship was tested for nitrogen fertilizer only because of a lack of indications concerning mineralization of organic nitrogen (table 3). 

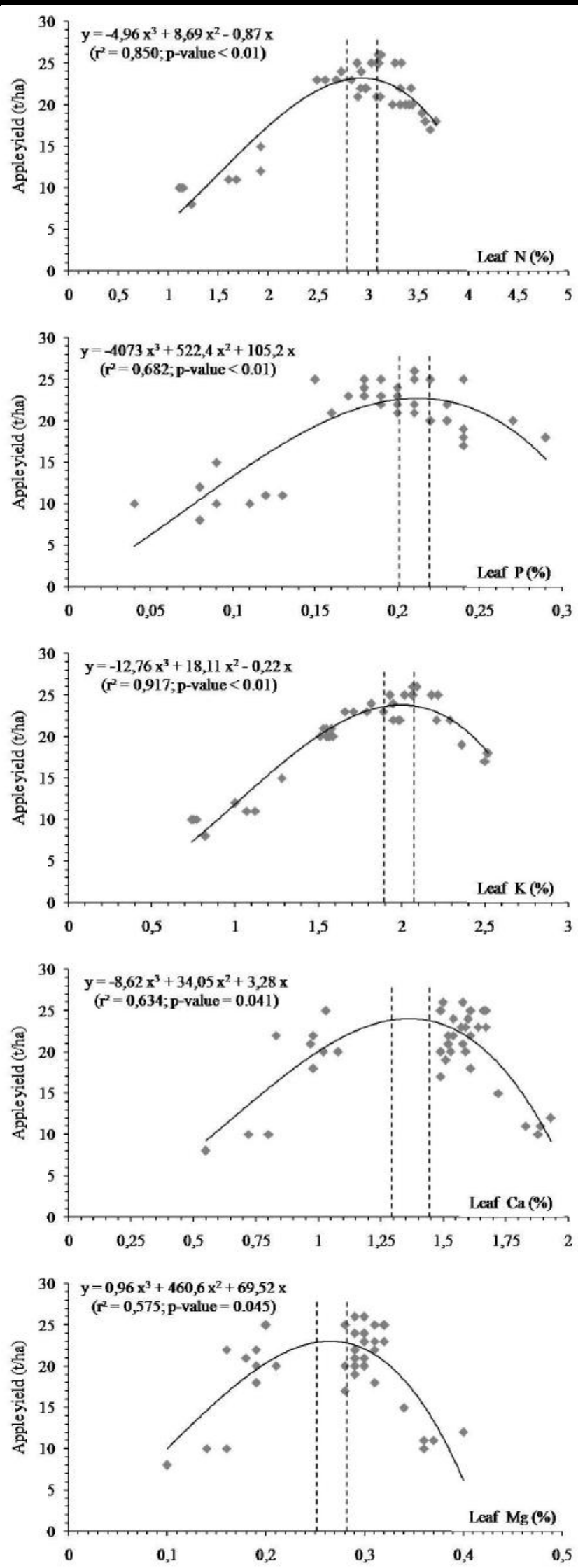

Fig. 2. Relationship between leaf nutrients content and apple yield 


\begin{tabular}{llllll}
\multicolumn{5}{c}{ Table.2. Ratios of different leaf nutrients in the productive apple orchards compared to the optimal values } \\
\hline Ratios & $\mathrm{N} / \mathrm{K}$ & $\mathrm{N} / \mathrm{Ca}$ & $\mathrm{K} / \mathrm{Ca}$ & $\mathrm{K} / \mathrm{Mg}$ & $\mathrm{Ca} / \mathrm{Mg}$ \\
\hline Min & 1.49 & 1.56 & 1.04 & 5.51 & 5.21 \\
\hline Max & 1.50 & 1.69 & 1.13 & 5.96 & 5.30 \\
\hline Mean & 1.50 & 1.63 & 1.08 & 5.73 & 5.26 \\
\hline Optimal values & $1.38-1.63$ & $2-2.38$ & $1.31-1.61$ & $6.55-8.40$ & $4.48-5.80$ \\
\hline French norms & $1.13-1.57$ & $1.13-1.68$ & $0.75-1.43$ & $4.29-9.09$ & $4.00-9.09$ \\
\hline United Kingdom norms & $1.50-2.15$ & $1.50-2.80$ & $0.81-1.60$ & $4.33-6.40$ & $3.33-6.40$ \\
\hline
\end{tabular}

Table.3: Relationship between nutrients content in soil and apple leaffollowing soil texture

\begin{tabular}{|c|c|c|c|c|}
\hline & Correlated factors & Regression equation & $\mathrm{r}^{2}$ & $\begin{array}{l}\text { Optimal level } \\
\text { in soil }\end{array}$ \\
\hline \multirow{5}{*}{ 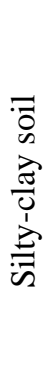 } & Fertilizer N (kg/ha) vs. Leaf N (\%) & $\mathrm{y}=0.526 \ln (\mathrm{x})+0.53$ & $0.58^{* *}$ & $74-130$ \\
\hline & Soil $\mathrm{P}_{2} \mathrm{O}_{5}(\mathrm{ppm})$ vs. Leaf $\mathrm{P}(\%)$ & $y=0.064 \ln (x)-0.09$ & $0.71^{* *}$ & $92-126$ \\
\hline & Soil $\mathrm{K}_{2} \mathrm{O}(\mathrm{ppm})$ vs. Leaf $\mathrm{K}(\%)$ & $y=1.187 \ln (x)-5.06$ & $0.77^{* *}$ & $350-415$ \\
\hline & Soil Ca (meq/100g) vs. Leaf Ca (\%) & $\mathrm{y}=0.552 \ln (\mathrm{x})-0.15$ & $0.83^{* *}$ & $14-18$ \\
\hline & Soil $\mathrm{Mg}(\mathrm{meq} / 100 \mathrm{~g})$ vs. Leaf $\mathrm{Mg}(\%)$ & $y=0.109 \ln (x)+0.19$ & $0.71^{* *}$ & $1.7-2.2$ \\
\hline \multirow{5}{*}{ 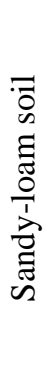 } & Fertilizer N (kg/ha) vs. Leaf N (\%) & $y=0.634 \ln (x)-0.07$ & $0.76^{* *}$ & $92-146$ \\
\hline & Soil $\mathrm{P}_{2} \mathrm{O}_{5}(\mathrm{ppm})$ vs. Leaf $\mathrm{P}(\%)$ & $y=0.074 \ln (x)-0.13$ & $0.87^{* *}$ & $82-106$ \\
\hline & Soil $\mathrm{K}_{2} \mathrm{O}(\mathrm{ppm})$ vs. Leaf K (\%) & $\mathrm{y}=0.809 \ln (\mathrm{x})-2.78$ & $0.57^{*}$ & $320-410$ \\
\hline & Soil Ca (meq/100g) vs. Leaf Ca (\%) & $y=0.481 \ln (x)-0.05$ & $0.86^{* *}$ & $13-18$ \\
\hline & Soil Mg (meq/100g) vs. Leaf Mg (\%) & $y=0.107 \ln (x)+0.19$ & $0.85^{* *}$ & $1.7-2.2$ \\
\hline
\end{tabular}

The results show that leaf contents in $\mathrm{N}, \mathrm{P}, \mathrm{K}, \mathrm{Ca}$ and $\mathrm{Mg}$ are significantly correlated with their corresponding soil contents both in silty-clay and sandy-loam soils. Such correlations were reported in several previous works [3133]. However, other trials reported that correlation is particularly low for phosphorus because of its low mobility in soil, thereby making its uptake limited at few millimeters from the hairy root $[22,34]$. The significance of the found correlation for this nutrient under the cultural conditions of the present study may be related to the submersion irrigation, which was able to increase the mobility of phosphorus in soil and making it more available for roots.

Furthermore, data show that the correlation coefficients in sandy-loam soil are higher than those found in silty-clay soil except for potassium. This result is in agreement with those of Fan and Yang [35] who indicated that uptake ability is higher in sandy soil for majority of nutrients owing to their increased mobility. Particularly, the high value of correlation coefficient found for nitrogen in sandy-loam soil indicates that there was no considerable leaching of this nutrient that is known to be important in sandy soil [36]. In clay soil, the uptake ability is particularly higher for potassium as result of its high fixation on clay particles and clay-humic complexes that ensure exchange of this nutrient in soil [37].

For each nutrient, the corresponding soil contents to ensure the leaf reference norms are considered as optimal soil contents to get high apple yield (table 2). The found optimal soil content for $\mathrm{P}, \mathrm{K}, \mathrm{Ca}$ and $\mathrm{Mg}$ may be considered as reference norms for soil analysis for apple orchards in the study region. While for nitrogen, the found values constitute the optimal amounts of nitrogen fertilizer for a high apple production with an average of $88 \mathrm{~kg} / \mathrm{ha}$ for apple orchards growing in silty-clay soil and of $130 \mathrm{~kg} / \mathrm{ha}$ for orchards in sandy-loam soil. These nitrogen doses are near of those recommended in Morocco by Mahhou [22] for Golden Delicious 30 years 
old and producing $40 \mathrm{t} / \mathrm{ha}$. They are also near amounts generally recommended in Western USA and Eastern Canada [38, 39]. However, they are higher than France recommendations averaged at $50 \mathrm{~kg} / \mathrm{ha}$ for an apple yield of $26 \mathrm{t} / \mathrm{ha}$ [40]. In fact, nitrogen dose vary following orchard situations. There is a significant disagreement in data on nitrogen amount used and removed by apple tree that is related to the differences in location, requirements of varieties and cultural practices [41]. Taking into account these considerations, the found optimal nitrogen doses concerns only the year of study and should be regarded as approximate for fertilizing apple tree in the region study for the next years.

Compared to the interpretation norms for soil test of Soltner [42], the found optimal nutrient contents in siltyclay soils are arranged in low level for $\mathrm{P}$, sufficient level for $\mathrm{K}$ and high level for $\mathrm{Ca}$ and $\mathrm{Mg}$. In sandy-loam soils, the optimal values are moderate for $\mathrm{P}$ and high for $\mathrm{K}, \mathrm{Ca}$ and $\mathrm{Mg}$. This disagreement may be related in large part to differences in yield level that is low compared to the production potential of the used variety that can reach 40 t/ha under optimal conditions [43]. This result imply that there were other factors that affect apple yield in the region study such as spring frosts, hail falls and inadequate cultural practices (irrigation, pruning, pests and diseases, etc.). Indeed, in previous diagnostic works carried out in the study region, it has been noted the existence of such factors that affect severely apple production $[44,45]$. Nevertheless, for an apple yield of 26 t/ha, the found optimal nutrient contents may be used as soil reference norms for the region study. By comparing these norms to soil analysis data, it appears that the soil richness in $\mathrm{K}, \mathrm{Ca}$ and $\mathrm{Mg}$ is able to satisfy the apple needs in these nutrients for all the tested orchards, thereby indicating that no intake in these nutrients is required. However, the intake of $\mathrm{P}$ is required since soil $\mathrm{P}$ content is low compared to found reference norms both in the silty-clay and sandy-loam soils (table 4).

Table.4: Recommended amounts of fertilizers $(\mathrm{kg} / \mathrm{ha})$ for an apple yield of $26 \mathrm{t} / \mathrm{ha}$

\begin{tabular}{llllll}
\hline & $\mathrm{N}$ & $\mathrm{P}_{2} \mathrm{O}_{5}$ & $\mathrm{~K}_{2} \mathrm{O}$ & $\mathrm{Ca}$ & $\mathrm{Mg}$ \\
\hline Orchards in silty-clay soil & 88 & 75 & 0 & 0 & 0 \\
Orchards in sandy-loam soil & 130 & 84 & 0 & 0 & 0 \\
\hline
\end{tabular}

\section{CONCLUSION}

In adult apple orchards growing in the middle Atlas of Morocco, there is an amply variation in yield level, applied amounts of fertilizers, soil richness in nutrient and their concentration in leaf. These variations originate from differences in cultural practices, especially fertilization since relationships between apple yield and nutrient content in soil and leaf were significant. The relationship between yield level and leaf nutrient content served to determine the reference norms for leaf analysis with regard to nitrogen, phosphorus, potassium, calcium and magnesium required to ensure a high apple yield under local climate, soil and cultural practices. Furthermore, relationship between leaf and soil nutrient content brought out local apple nitrogen needs and reference norms of soil analysis for $\mathrm{P}, \mathrm{K}, \mathrm{Ca}$ and $\mathrm{Mg}$. However, it should be highlighted that the found results are in preliminary order since the study was conducted during one year. The results are also in elementary order for establishment of the Moroccan reference norms for leaf and soil analysis in apple orchards.

\section{REFERENCES}

[1] Spiertz, H. (2013). Challenges for crop production research in improving land use, productivity and sustainability. Sustainability, 5(4).1632-1644.
[2] Mckenzie, R. (1998). Crop nutrition and fertilizer requirements. Agriculture, Food and Rural Development, 540(1).1-7.

[3] Laboski, C.A.M and Piters, J.B. (2012). Nutrient application guidelines for field, vegetable and fruit crops in Wisconsin. Ed. University of Winconsin Extension. 94 pages.

[4] Cate, R.B.J.R. and Nelson, L.A. (1965). A rapid method for correlation of soil test analysis and plant response data, North Carolina International soil testing series bulletin. 1.13 pages

[5] Neyroud, J.A., Amiguet S., Andrey G., Evequoz C. (2007). Le diagnostic foliaire en arboriculture : bilan de 20 ans d'étude. Revue Suisse Viticulture, Arboriculture Horticulture. 39(5).307-313.

[6] Granatstein, D. and Sanchez, E. (2009). Research Knowledge and Needs for Orchard Floor Management. International Journal of Fruit Science. 9(3).257-281.

[7] Neilsen, G.H. and Neilsen, D. (2003). Nutritional requirements of apple. In: Ferree, D.C and Warrington I.J. Apples: botany, production, and uses. CABI Publishing, Cambridge. 267-302.

[8] Von Wandruszka, R. (2006). Phosphorus retention in calcareous soils and the effect of organic matter on its mobility. Geochemical Transactions. 7(6).1-8. 
[9] Ebdon, J.S., Petrovic A.M., White R.A. (1999). Interaction of nitrogen, phosphorus, and potassium on evapotranspiration rate and growth of kentucky bluegrass. Crop Science. 39(1).209-218.

[10] Ordonez J.C., Van Bodegom, P.M., Witte J.M., Wright, I.J., Reich P.B., Aerts, R. (2009). A global study of relationships between leaf traits, climate and soil measures of nutrient fertility. Global Ecology and Biogeography. 18(2).137-149.

[11] Day, R. (1965). Particle Fractionation and ParticleSize Analysis. In: Black C.A. Methods of Soil Analysis. American Society of Agronomy, Madison, Wisconsin, USA. 546-566.

[12] Drouineau, G. (1942). Rapid determination of the active limestone soil. Reportation new data on the nature of the limestone fractions. Annals of Agronomy. 12.441-450.

[13] Baize, D. (2000). Guide des analyses en pédologie. Institut National de la Recherche Agronomique, France. 266 pages.

[14] Allison, L.E. (1965). Organic Cabon. In: Black C.A. Methods of soil analysis. American Society of Agronomy, Madison, Wisconsin, USA.1372-1376.

[15] Rayan, J., Garabet S., Harmsen K., Rashid A. (1996). A soil and plant analysis manual adapted for the west Asia and north Africa region. ICARDA, Aleppo. 244 pages.

[16] Joret, G. and Hebert, J. (1955). Contribution à la détermination $\mathrm{du}$ besoin des sols en acide phosphorique. Annals of Agronomy.2.233-299.

[17] Chapman, H.D. (1965). Cation-exchange capacity. In: Black C. A. Methods of soil analysis. American Society of Agronomy, Madison, Wisconsin, USA.891-903.

[18] Allison, L.E. and Moodie C.D. (1965). Carbonate. In: Black C. A. Methods of soil analysis. American Society of Agronomy, Madison, Wisconsin, USA.621-633.

[19] Cheng, L. and Raba, R. (2009). Accumulation of macro- micronutrients, and nitrogen demand-supply relationship of 'Gala' /'Malling 26' apple trees grown in sand culture. Journal of the American Society for Horticultural Science. 134(1).3-13.

[20] Raina S.K., Dar M.A, Wani J.A, Bhat M.Y., Malik M.A. (2014). Relationship of leaf nutrient content with fruit yield and quality of pear. Journal of Environmental Biology. 36(3).649-653.

[21] Kumar T.S, Kumar J., Kumar M. (2007). Effect of leaf nutrient status on yield and quality of kiwi fruit (Actinidia deliciosal Chev.). Indian Journal of Horticulture. 64(2).77-88.
[22] Mahhou, A. (2008). Fertilisation des rosacées fruitières. Bulletin Mensuel d'Information et de Liaison du Programme National de Transfert de Technologie en Agriculture. 165. 4 pages.

[23] Oukabli, A. (2004). Le pommier: une culture de terroir en zones d'altitude. Bulletin Mensuel d'Information et de Liaison du Programme National de Transfert de Technologie en Agriculture. 115. 4 pages.

[24] Bould, C. (1969). Leaf analysis as a guide to the nutrition of fruit crops. Journal of the Science of Food and Agriculture. 20(3).172-181.

[25] Kenworthy, A.L. (1961). Interpreting the balance of nutrient elements in leaves of fruit trees. In: plant analysis and fertilizer problems. American Horticultural Biology Science. 28-33.

[26] Holb, I.J. and Nagy P.T. (2006). Study on the macronutrient content of apple leaves in an organic apple orchard. Journal of Central European Agriculture.7(2).329-336.

[27] Racsko J., Szabo Z., Nyeki J. (2005). Effect of nutrient supply on fruit quality of apple (Malus domestica borkh.). Journal of Central European Agriculture, 6(1).35-42.

[28] Morgan, J.B. and Connolly, E.L. (2013). Plant-Soil Interactions: Nutrient Uptake. Nature Education Knowledge 4(8).2.

[29] Hao, X. and Papadopoulos, A.P. (2004). Effects of calcium and magnesium on plant growth, biomass partitioning and fruit yield of winter greenhouse tomato. HortScience, 39(3).512-515.

[30] Ige D.V., Akinremi O.O., Flaten D.N. (2007). Direct and Indirect Effects of Soil Properties on Phosphorus Retention Capacity. Soil Science Society of America Journal 71(1).95-100.

[31] Thamrin M., Susanto S., Susila A.D., Sutandi D.A. (2014). Correlation between nitrogen, phosphorus and potassium leaf nutrient with fruit production of pummelo citrus (Citrus maxima). Asian Journal of Applied Sciences. 7(3).129-139.

[32] Ben Hassine H. and Ben Mustapha A. (2014). Effect of the Phosphate Fertilization on the Production of Apple Trees Planted in Calcareous Alluvial Soil. International Journal of Multidisciplinary and Current Research. 2(7).812-817.

[33] Zydlik, Z. and Pacholak E. (2006). The effect of climatic and soil conditions on the mineral composition in the leaves of apple tree cultivars depending on the term of their fruit ripening. Latvian Journal of Agronomy. 9.172-176. 
[34] Frink, C.R. (1965). Apple orchard soil and leaf analysis. Connecticut Agricultural experiment station Bulletin. 670.1-11.

[35] Fan, W. and Yang, H. (2011). Effect of soil type on root architecture and nutrient uptake by roots of young apple rootstocks. Acta Horticulturae. 903.885-890

[36] Burgos P., Madejon E., Cabrera F. (2006). Nitrogen mineralization and nitrate leaching of a sandy soil amended with different organic wastes. Waste Management and Research. 24(2).175-182.

[37] Najafi-Ghiri, M and Abtah A. (2013). Potassium Fixation in Soil Size Fractions of Arid Soils. Soil and Water Research. 8(2).49-55

[38] Anonymous. (1998). Western Fertilizer Handbook. $2^{\text {nd }}$ Ed. California Fertilizer Association, Sacramento. 362 pages.

[39] Anonymous. (2012). Fertilisation des nouveaux vergers de pommier en Ontario. Ministère de l'Agriculture, de l'Alimentation et des Affaires Rurales, Canada, 7pages.

[40] Sevely, C. (2008). Fiche technique pomme: production développée en Languedoc Roussin. Chambre d'Agriculture de l'Hérault. 8 pages.

[41] Wrona, D. (2004). Effect of nitrogen fertilization on growth, cropping and fruit quality of Sampion apple trees during 9 years after planting. Folia Horticulturae Annals. 16(1).55-60

[42] Soltner, D. (2000). Les bases de la production végétale: le sol et son amélioration. Sciences et Techniques Agricoles, Saint-Gemmes-Sur-Loire, France. 472 pages.

[43] Veverka, V. and Pavlacka, R. (2012). The effect of drip irrigation on the yield and quality of apples. Acta Universitatis Agriculturae et Silviculturae Mendelianae Brunensis, 29(8).247-252.

[44] Razouk, R. (2001). Diagnostic de la conduite de la fertilisation et de l'état nutritionnel du pommier dans la région d'Imouzzare. Mémoire de fin d'étude, Ecole Nationale d'Agriculture, Meknès, Morocco. 102 pages.

[45] Anonymous. (2006). Utilisation des engrais par culture au Maroc. Food and Agriculture Organization, Rome. 73 pages. 